\title{
ESTUDO DA ESTABILIDADE DE TALUDES RODOVIÁRIOS DA BR-393
}

\section{José Branham Ribeiro de Lima' \\ Isabelle de Melo Vicente ${ }^{2}$ \\ Júlio César da Silva ${ }^{3}$}

Resumo: A geotecnia tem sido essencial para o avanço da expansão territorial, acessos rodoviários e ferroviários, portos e estruturas profundas como túneis e exploração de minérios. Sua influência e análise tem apresentado bons resultados no aprimoramento de obras mais seguras. O desenvolvimento de estudos e métodos em estabilidade permitem avaliar a resistência de taludes, culminando em uma melhor solução às rupturas causadas pelos fatores da natureza (chuvas orográficas, ciclônicas e convectivas). O avanço tecnológico e a implantação de ferramentas digitais, como o SLOPEN da GEO-SLOPE, potencializaram os métodos de análise de estabilidade de taludes e os tornou rápidos e eficientes. Com isto, identificado o fator de segurança, com o apoio do software, referente a um talude rodoviário na BR-393, pôde-se determinar o fator de segurança associado e indicar o tipo de contenção que melhor se adaptasse, com rapidez e eficácia, minimizando os riscos de taludes rodoviários.

Palavras-chave: Estabilidade; Talude; Ruptura; Análise; Segurança.

\footnotetext{
${ }^{1}$ Engenharia Civil/Universidade do Grande Rio (UNIGRANRIO), Brasil. E-mail: branhamlima@hotmail.com. ${ }^{2}$ Engenharia Civil/Universidade Severino Sombra (USS), Brasil. E-mail: isabelleolimpia@hotmail.com. ${ }^{3}$ Engenharia Civil/Universidade do Grande Rio (UNIGRANRIO), Brasil. E-mail: jcesarop@gmail.com.
} 